\title{
Políticas de igualdade racial e suas interfaces com a Educação Indígena, do Campo e Quilombola: reivindicações históricas e conquistas dos movimentos sociais
}

\author{
Racial equality policies and their interfaces with Indigenous, Rural and Quilombola Education: \\ historical demands and achievements of social movements
}

Politiques d'égalité raciale et leurs interfaces avec l'éducation indigène, rurale et quilombola: exigences historiques et réalisations des mouvements sociaux

Gilberto Paulino de Araújo ${ }^{1}$ Universidade Federal do Tocantins

Antônio Cláudio Moreira Costa ${ }^{2}$ Universidade Federal de Uberlândia

Salomão Antônio Mufarrej Hage ${ }^{3}$ Universidade Federal do Pará

Resumo: O artigo apresenta uma discussão sobre as políticas de igualdade racial e suas interfaces com a Educação Indígena, do Campo e Quilombola no Brasil. A análise tem como foco as reivindicações históricas e as conquistas dos movimentos sociais representativos dos povos tradicionais, indígenas e camponeses. A metodologia fundamenta-se na pesquisa bibliográfica e documental, tendo como base a revisão de autores que tratam da temática em pauta, assim como as legislações que reconhecem o direito à educação desses povos. Dentre os resultados, destacamos o papel dos movimentos sociais no surgimento e fortalecimento das políticas públicas de igualdade racial, de Educação Indígena, do Campo e Quilombola como instrumentos de resistência e (re)existência à lógica capitalista.

Palavras-Chave: Políticas de Igualdade Racial. Educação Indígena. Educação do Campo. Educação Quilombola. Movimentos Sociais.

Abstract: The paper presents a discussion on racial equality policies and their relations with indigenous, rural and 'quilombola' Education in Brazil. The analysis focuses on the historical demands and achievements of indigenous and peasants' notorious social movements. The methodology is based on bibliographic and documental research, reviewing authors who deal with this theme. Furthermore, the laws recognizing rights to education of these people will also be considered. It is worth noting among the results the role of social movements in emergence

1 Gilberto Paulino de Araújo. Doutor em Linguística - Programa de Pós-Graduação em Linguística da Universidade de Brasília (PPGL/UnB - Brasil). Professor Adjunto do Curso de Licenciatura em Educação do Campo da Universidade Federal do Tocantins (UFT/Câmpus Arraias). E-mail: gilbertopaulino@uft.edu.br. Lattes: http://lattes.cnpq.br/3619414510173162. ORCID: https://orcid.org/O000-0002-4519-713X.

2 Antônio Cláudio Moreira Costa. Doutor em Educação. Professor Associado da Faculdade de Educação FACED, da Universidade Federal de Uberlândia. Coordenador do Grupo de Estudos e Pesquisas em Educação, Cultura e Comunicação - GEPECC. Pós-doutorando na Faculdade de Psicologia e Educação da Universidade do Porto / Portugal. E-mail: acmoreira@ufu.br. Lattes: http://lattes.cnpq.br/2572632795045384. ORCID: https://orcid.org/0000-0001-9534-0056.

3 Salomão Antônio Mufarrej Hage. Doutor em Educação pela PUC de São Paulo. Professor do Instituto de Ciências da Educação da Universidade Federal do Pará. Bolsista Produtividade do CNPQ. Coordenador do Grupo de Estudos e Pesquisas em Educação do Campo na Amazônia (GEPERUAZ). Integra a Coordenação do Fórum Paraense de Educação do Campo. E:mail: salomao_hage@yahoo.com.br. Lattes: http://lattes.cnpq.br/1723722364556016. ORCID: https://orcid.org/0000-0001-7801-0696. 
and strengthening of public policies of racial equality, and indigenous, rural and 'quilombola' Education as instruments of resistance and (re)existence against the capitalist logic.

Key Words: Racial Equality Policy. Indigenous Education. Rural Education. 'Quilombola' Education. Social Movement.

Résumé: Le article présente une discussion sur les politiques d'égalité raciale et leurs interfaces avec l'éducation indigène, rurale et quilombola au Brésil. L'analyse se concentre sur les demandes et les réalisations historiques des mouvements sociaux représentatifs des peuples traditionnels, indigènes et paysans. La méthodologie est basée sur une recherche bibliographique et documentaire, ayant comme référence la revue des auteurs qui traitent du sujet en question, ainsi que sur les lois qui reconnaissent le droit à l'éducation de ces peuples. Parmi les résultats, nous soulignons le rôle des mouvements sociaux dans l'émergence et le renforcement des politiques publiques d'égalité raciale, d'éducation indigène, rurale et quilombola comme instruments de résistance et de (ré)existence à la logique capitaliste.

Mots-clés: Politiques d'égalité raciale. Éducation autochtone. Éducation rurale. Éducation de Quilombola. Mouvements sociaux.

Recebido em: 01 de junho de 2020 Aceito em: 11 de julho de 2020

\section{Introdução}

Este artigo apresenta uma discussão sobre as políticas de igualdade racial e suas interfaces com a Educação Indígena, com a Educação do Campo e com a Educação Quilombola, analisando-as a partir de reivindicações históricas e de conquistas dos movimentos sociais representativos dos povos tradicionais, indígenas e camponeses. Embora seja assegurado na Constituição Federal de 1988, no Art. $5^{\circ}$ que: “Todos são iguais perante a lei, sem distinção de qualquer natureza, garantindo-se aos brasileiros e aos estrangeiros residentes no País a inviolabilidade do direito à vida, à liberdade, à igualdade, à segurança e à propriedade”, esse direito tem sido negligenciado pelos entes federativos e pouco reconhecido pela população brasileira, sobretudo a classe média alta e branca, que imagina ser superior à população pobre, negra, indígena, quilombola, camponesa. Por isso, as políticas de igualdade racial, de Educação Indígena, Quilombola e do Campo são necessárias para garantir e efetivar os direitos constitucionais dos povos tradicionais, indígenas e camponeses.

Neste texto, seguindo as orientações do Decreto $n^{\circ} 7.352 / 2010$ (Art. $1^{\circ}, \S 1^{\circ}$ ), da Presidência da República, compreendemos por populações do campo: os agricultores familiares, os extrativistas, os pescadores artesanais, os ribeirinhos, os assentados e acampados da reforma agrária, os trabalhadores assalariados rurais, os quilombolas, os 
caiçaras, os povos da floresta, os caboclos e outros que produzam suas condições materiais de existência a partir do trabalho no meio rural. Por isso, propomo-nos a analisar as políticas educacionais que envolvem essas populações, em suas especificidades, que se diferenciam das populações urbanas e precisam ser visibilizadas e afirmadas.

A metodologia empregada possui caráter bibliográfico e documental. Dialogamos com Souza (2008) ao tratarmos das políticas educacionais voltadas para os povos tradicionais, indígenas e camponeses, definidas com a participação de movimentos sociais representativos desses povos; e com Barbosa (2011), Iberê (2015) e Santos (2018) ao abordarmos as consequências do capitalismo na América Latina - embora este não seja o foco do estudo proposto, tais autores nos auxiliaram na compreensão da relevância das políticas afirmativas e de igualdade racial no cenário brasileiro.

Utilizamos a análise documental, priorizando as legislações mais recentes que reconhecem o direito à educação desses povos e algumas produções resultantes de encontros por eles realizados. Contou ainda de forma significativa para o adensamento da discussão, o acúmulo que temos obtido com estudos e ações referentes a essa temática e com esses povos no âmbito de nossos grupos de pesquisa, vinculados aos programas de Pós-Graduação dos quais fazemos parte ${ }^{4}$.

O artigo está organizado em duas partes: primeiramente refletimos sobre as políticas públicas para a igualdade racial e suas interfaces com a Educação Quilombola, Indígena e do Campo, analisando as principais conquistas dos movimentos sociais nesse campo; e, posteriormente, refletimos sobre as ameaças que têm sido impostas às políticas em tela.

\section{O papel dos movimentos sociais e as conquistas no âmbito das políticas públicas}

As políticas públicas de igualdade racial no Brasil revelam a trajetória de resistência e (re)existência da luta dos movimentos sociais, especificamente no decorrer das últimas décadas do século XX e início do século XXI. No amplo e complexo campo das relações humanas na contemporaneidade, permanece, ainda hoje, o esforço para superar as várias formas de poder ou hegemonia global que regem as questões políticas, econômicas, sociais e, também, acadêmicas.

No que diz respeito aos elementos históricos, é preciso considerar as consequências da colonização dos povos da África e das Américas, isto é, os efeitos materiais e simbólicos da

\footnotetext{
${ }^{4}$ Na mesma ordem de autoria do texto seguem os grupos de estudos e pesquisas certificados pelo Conselho Nacional de Desenvolvimento Científico e Tecnológico (CNPq): Grupo de Pesquisa Sociolinguística, Letramentos Múltiplos e Educação (SOLEDUC); Grupo de Estudos e Pesquisas em Educação, Cultura e Comunicação - GEPECC; Grupo de Estudos e Pesquisas em Educação do Campo na Amazônia (GEPERUAZ).
} 
demasiada exploração da natureza e subjugação dos grupos étnicos que aqui viviam e os que foram escravizados e trazidos para este continente.

Uma das obras que discute tais questões é "IIRSA: a serpente do capital: pilhagem, exploração e destruição cultural na América Latina (Santo Antônio e Jirau), do pesquisador e liderança indígena Daniel Iberê. O autor apresenta uma crítica aos discursos e práticas colonizadoras, presentes ainda hoje em nossa sociedade, que desconsideram os saberes dos povos tradicionais e ignoram tudo aquilo que foi historicamente construído em relação às artes, à educação, à medicina, isto é, o patrimônio cultural que existia e foi produzido muito antes da chegada dos colonizadores ao território americano.

A consagração do esquecimento, a que os latino-americanos estão submetidos, antecipa e delata a amputação sofrida, por milhões de indivíduos, de parte essencial de suas memórias. Foram desarraigadas e dilaceradas as escritas astecas e maias, pinturas, esculturas, canções, composições musicais, fórmulas médicas, ferramentas, instrumentos, miríades de artigos - que constituíam o patrimônio cultural determinante dos fazeres e saberes simbólicos e dos modos de compreensão e interpretação da realidade dos povos dessas terras, atualmente conhecidas como América (IBERÊ, 2015, p. 77).

Chamamos atenção ao fato de que, ainda que o processo de colonização tenha se extinguido nos países latinos e africanos, os vestígios do colonialismo, as artimanhas da colonialidade ainda são muito marcantes e fazem com que a tão sonhada liberdade e igualdade entre os seres humanos ainda seja uma utopia. Barbosa (2011) fundamenta nossa afirmação ao assinalar que:

O colonialismo não é coisa nova. É coisa velha. Já existia há três mil anos atrás. Ele não é algo ao acaso. Trata-se de uma política de um Estado. Beneficia um povo contra outro povo. Enriquece a classe dominante do povo explorador do outro. Há uma cumplicidade na nação dominadora, contra a nação dominada. Sendo arma de um povo contra outro, não é "apenas" um "problema social" e "econômico". É fundamentalmente um problema étnico e cultural. Tal política acaba jogando para baixo as etnias, as economias e as culturas dos povos que foram dominados e, em seguida, colonizados (BARBOSA, 2011, p. 7).

A partir dessas considerações, fica evidenciado que as estratégias colonialistas ainda estão presentes, sobrevivendo ao tempo, se metamorfoseando de modo a não serem identificadas. Os processos de socialização a que estamos submetidos nos incutem a ideia de que o colonialismo foi superado e pensar contrário a isso é manter-se numa posição apocalíptica, sem considerar todos os avanços que tivemos.

$\mathrm{Na}$ idade moderna, dada a persistência da ideia do progresso, uma das maiores dificuldades em captar o espírito de uma dada época reside em 
identificar as continuidades com épocas anteriores, quase sempre disfarçadas de descontinuidades, inovações, rupturas. O que permanece de períodos anteriores é sempre metamorfoseado em algo que simultaneamente o denuncia e dissimula e, por isso, permanece sempre como algo diferente do que foi sem deixar de ser o mesmo [...]. O que terminou com os processos de independência do século XX foi uma forma específica de colonialismo, e não o colonialismo como modo de dominação. A forma que terminou foi o que se pode designar por colonialismo histórico caracterizado pela ocupação territorial estrangeira. Mas o modo de dominação colonial continuou sob outras formas. O colonialismo como modo de dominação assente na degradação ontológica das populações dominadas por razões etno-raciais está hoje tão vigente e violento como no passado (SANTOS, 2018, s/p).

Vale lembrar que as ciências e a educação muitas vezes estiveram predominantemente a serviço dessa lógica de organização política, econômica e social pautada em práticas racistas e discriminatórias conhecidas como colonialismo. Livros didáticos que reproduziam (e reproduzem) a história contada sob a perspectiva do colonizador, transmitindo ou supondo uma superioridade branca/ocidental. Numa postura de conformismo e submissão, coloca os povos africanos, indígenas e camponeses numa posição de inferioridade, de modo a desconsiderar e, até mesmo, invalidar os saberes originários: as lições de preservação da natureza, o respeito à ancestralidade e ao sagrado, o convívio com a diversidade linguística, biológica e cultural, a valorização das memórias etc.

Embora a realidade seja muito mais complexa, a efetivação e permanência das políticas públicas são elementos importantes no combate às estruturas de poder colonialistas que se mantém apoiadas na exploração, no genocídio e no etnocídio dos povos originários. Num contexto marcado pelo imperialismo, as políticas colonialistas atuais

\begin{abstract}
[...] buscam, em uma corrida desenfreada, dominar os últimos recônditos dos recursos naturais, o que envolve a pilhagem dos rios e das águas, dos minérios e das terras, da dignidade e da vida de mulheres e homens, camponeses e ribeirinhos e ribeirinhos camponeses, garimpeiros e pescadores, povos originários que a linguagem reduz e homogeneíza a um único termo: "índios", reduzidos ao silêncio e a não-existência na longa noite dos desterros, termo ao mesmo tempo sinônimo de todos e de ninguém, linguagem cristalizadora de um mundo de complacências e submissões, que reduz todos os universos de conhecimentos, os costumes, as singularidades, as particularidades a um único não-ser caricatural, falseado, estereotipado e incorporado à lógica alienante do grande capital mundial, um claro exemplo da ganância corporativa colocada à frente dos interesses sociais gerais da população (IBERÊ, 2015, p. 40).
\end{abstract}

Os pressupostos apontados por Iberê (2015) reforçam nossa tese de que o colonialismo no Brasil como modo de dominação baseada na degradação da natureza e das populações tradicionais encontra-se hoje tão explícito e violento como em tempos anteriores. Os povos indígenas, quilombolas e camponeses, embora sejam incluídos nas declarações 
universais dos direitos humanos, continuam sendo invisibilizados, muitas vezes considerados sub-humanos, seres inferiores na escala do ser, sem cultura, atrasados, incivilizados.

As ideias de Iberê (2015) convergem com as de Santos (2018) acerca dos impactos nocivos dos processos colonizadores sobre os povos indígenas, quilombolas e camponeses. Santos é categórico ao afirmar que:

Foram concebidos como parte da paisagem das terras "descobertas" pelos conquistadores, terras que, apesar de habitadas por populações indígenas, foram consideradas como terras de ninguém. Foram também considerados como objectos de propriedade individual, de que é prova histórica a escravatura. E continuam hoje a ser populações e corpos vítimas do racismo, da xenofobia, da expulsão das suas terras para abrir caminho aos megaprojectos mineiros e agro-industriais e à especulação imobiliária, da violência policial e das milícias paramilitares, do tráfico de pessoas e de órgãos, do trabalho escravo designado eufemisticamente como "trabalho análogo ao trabalho escravo", da conversão das suas comunidades de rios cristalinos e florestas idílicas em infernos tóxicos de degradação ambiental. Vivem em zonas de sacrifício, a cada momento em risco de se transformarem em zonas de não-ser (SANTOS, 2018, s/p).

As considerações feitas por Santos (2018) e Iberê (2015) são fundamentais para a compreensão dos processos históricos de exploração dos grupos étnico-raciais escravizados a partir de modelos político-econômicos pautados na espoliação dos territórios dominados/colonizados. Todavia, faz-se mister notar a sutil diferença entre processo colonial e processos neocoloniais. A respeito disso, Barbosa chama nossa atenção para o fato de que:

O velho colonialismo estava baseado no capital mercantil. O Estado dele resultante era mais fraco e as situações históricas por ele geradas eram mais instáveis. O novo colonialismo viu-se baseado no capital industrial. Como explicava Hobsbawm, ele precisa não só retirar riquezas da colônia e acumulá-las na metrópole, como vender quantidades consideráveis de produtos industriais para as populações colonizadas. Portanto, o novo colonialismo não pode apenas desorganizar as sociedades e suas vítimas, retirando-lhes tudo que possa transformar em mercadoria, inclusive a pessoa humana. O novo colonialismo precisa organizar a sociedade das vítimas, para ter a mesma - ou quase a mesma cultura - do explorador. Só assim ele - a vítima - deixará de ser um explorado passivo e irá se transformar em um explorado ativo. Isto é, um explorado que apóia e coopera com o neocolonialista para a destruição de sua própria cultura e de sua própria nação. Os efeitos da revolução industrial criaram, portanto, a necessidade do neocolonialismo. E enquanto permanecer a relação de forças por ela gerada em nível mundial, o conceito de neocolonialismo será atual. Ele corresponde a toda uma etapa histórica da sociedade. A partilha da África no final do século XIX é um momento do neocolonialismo. A abolição da escravidão no Brasil é um momento do neocolonialismo. A negação dos direitos dos negros e dos indígenas na América Latina é outro momento do neocolonialismo, etc. O Estado mais forte da sociedade industrial permite não só colonizar as terras do outro, mas de modo plural, a alma do outro (BARBOSA, 2011, p. 8). 
A partir desses pressupostos, podemos inferir, conforme apontamos anteriormente, que os processos colonialistas ainda estão em curso, mas com discursos adequados ao momento histórico, por isso sua identificação torna-se mais complexa, precisando de que examinemos os fenômenos sociais para além das aparências, a fim de chegarmos à sua essência. A respeito disso, Santos corrobora:

As novas formas de colonialismo são mais insidiosas porque ocorrem no
âmago de relações sociais dominadas pelas ideologias do anti-racismo, dos
direitos humanos universais, da igualdade de todos perante a lei. O
colonialismo insidioso é gasoso e evanescente, tão invasivo quanto evasivo,
em suma, ardiloso. Mas nem por isso engana ou minora o sofrimento de
quem é dele vítima na sua vida quotidiana. Floresce em apartheids sociais
não-institucionais mesmo que sistemáticos. Ocorre nas ruas e nas casas, nas
prisões e nas universidades, nos supermercados e nas esquadras de polícia.
Disfarça-se facilmente de outras formas de dominação tais como diferenças
de classe, sexo ou sexualidade (SANTOS, $2018, \mathrm{~s} / \mathrm{p}$ ).

Ter consciência desses processos é importante para se vislumbrar possibilidades de interferir nessa realidade, na perspectiva de romper com o estigma de vítimas que nos impuseram. Os povos latinos e africanos não devem renunciar à expressão de sua narrativa da história, não devem deixar de denunciar aqueles que orientados pela cobiça inerente à lógica capitalista exterminaram milhões de seres humanos e destruíram a natureza.

Diante disso, destacamos o papel dos movimentos sociais que, historicamente, têm lutado pela construção e fortalecimento de políticas públicas capazes de realizar intervenções profícuas na elaboração e execução de ações voltadas à garantia dos direitos humanos e sociais, da justiça social, da sustentabilidade ambiental e do respeito à diversidade cultural, religiosa e linguística.

Cumpre ressaltar o protagonismo dos militantes desses movimentos: sujeitos do campo, mestres quilombolas e lideranças indígenas responsáveis pelo compartilhamento de saberes, experiências, tradições e muitos outros elementos culturais e religiosos que ultrapassam fronteiras e alcançam novos territórios por meio da Educação Popular, da Educação do Campo, da Educação Étnico-Racial, da Educação Quilombola, da Educação Indígena, entre muitas outras e suas epistemologias.

Dentre as conquistas resultantes das intervenções dos movimentos sociais, em especial, do Movimento Negro e Indígena, podemos destacar as Leis 10.639/2003 e 11.645/2008 - políticas públicas que reconhecem as diversidades étnico-raciais e culturais, nos remetendo ao combate ao racismo e à discriminação social.

A Lei 10.639/2003 estabelece a obrigatoriedade do ensino de História e Cultura AfroBrasileira e Africana na educação básica, tendo em vista assegurar o direito à igualdade de 
condições de vida e de cidadania, a igualdade de direitos às histórias e culturas que compõem a nação brasileira, assim como o direito de acesso às diferentes fontes da cultura nacional a todos os brasileiros (BRASIL, 2006).

Em 2004, o Conselho Nacional de Educação/Conselho Pleno instituiu as Diretrizes Nacionais para a Educação das Relações Étnico-Raciais e para o Ensino de História e Cultura Afro-Brasileira e Africana (CNE/CP Resolução 1/2004). Dentre as observações que constam em seus artigos relacionadas à inclusão de conteúdos, disciplinas e/ou atividades curriculares a serem seguidas pelas instituições de ensino nos diferentes níveis e modalidades, destacamos o Artigo $5^{\circ}$ :

\begin{abstract}
Os sistemas de ensino tomarão providências no sentido de garantir o direito de alunos afrodescendentes de frequentarem estabelecimentos de ensino de qualidade, que contenham instalações e equipamentos sólidos e atualizados, em cursos ministrados por professores competentes no domínio de conteúdos de ensino comprometidos com a educação de negros e não negros, sendo capazes de corrigir posturas, atitudes, palavras que impliquem desrespeito e discriminação. (BRASIL, 2004, s/p).
\end{abstract}

A menção ao Artigo $5^{\circ}$ da referida diretriz (CNE/CP Resolução 1/2004) é feita com vistas a relacionar as políticas públicas que, de algum modo, dialogam e propiciaram uma maior inserção de estudantes indígenas, quilombolas e camponeses em cursos da educação superior, à exemplo da Licenciatura em Educação do Campo e da Licenciatura Intercultural Indígena.

No que diz respeito à Lei 11.645/2008, esta altera a Lei 9.394/1996, modificada pela Lei no 10.639, de 9 de janeiro de 2003, que estabelece as Diretrizes e Bases da Educação Nacional, para incluir no currículo oficial da rede de ensino a obrigatoriedade da temática "História e Cultura Afro-Brasileira e Indígena":

$\S 1$ O O conteúdo programático a que se refere este artigo incluirá diversos aspectos da história e da cultura que caracterizam a formação da população brasileira, a partir desses dois grupos étnicos, tais como o estudo da história da África e dos africanos, a luta dos negros e dos povos indígenas no Brasil, a cultura negra e indígena brasileira e o negro e o índio na formação da sociedade nacional, resgatando as suas contribuições nas áreas social, econômica e política, pertinentes à história do Brasil.

§ 2 o Os conteúdos referentes à história e cultura afro-brasileira e dos povos indígenas brasileiros serão ministrados no âmbito de todo o currículo escolar, em especial nas áreas de educação artística e de literatura e história brasileiras. (BRASIL, 2008, s/p).

Outro importante documento é a Resolução $\mathrm{n}^{\circ}$ 8, de 20 de novembro de 2012, que define as Diretrizes Curriculares Nacionais para a Educação Escolar Quilombola na 
Educação Básica (Conselho Nacional de Educação / Câmara de Educação Básica $\mathrm{CNE} / \mathrm{CEB}$ ), como pode ser observado em próprio texto:

III - destina-se ao atendimento das populações quilombolas rurais e urbanas em suas mais variadas formas de produção cultural, social, política e econômica;

IV - deve ser ofertada por estabelecimentos de ensino localizados em comunidades reconhecidas pelos órgãos públicos responsáveis como quilombolas, rurais e urbanas, bem como por estabelecimentos de ensino próximos a essas comunidades e que recebem parte significativa dos estudantes oriundos dos territórios quilombolas;

$\mathrm{V}$ - deve garantir aos estudantes o direito de se apropriar dos conhecimentos tradicionais e das suas formas de produção de modo a contribuir para o seu reconhecimento, valorização e continuidade;

VI - deve ser implementada como política pública educacional e estabelecer interface com a política já existente para os povos do campo e indígenas, reconhecidos os seus pontos de intersecção política, histórica, social, educacional e econômica, sem perder a especificidade. (BRASIL, 2012, s/p).

É claro que no campo da prática ainda há um longo caminho a percorrer, tendo em vista as ações para a efetiva implementação dessas legislações: produção de material didático, formação inicial e continuada de professores, melhoria da infraestrutura das escolas, ampliação do número de instituições de ensino em áreas quilombolas (rurais e urbanas) e indígenas (ou mesmo o impedimento do fechamento de escolas nas comunidades camponesas), entre outros aspectos políticos e sociais fundamentais.

Por outro lado, devemos ressaltar a importância de todos estes documentos que afirmam os princípios e orientações que fundamentam o reconhecimento e a valorização da identidade, história e cultura indígena, africana e afro-brasileira, assim como a promoção de uma educação pautada na pluralidade étnico-racial.

Nesse sentido, as políticas públicas de igualdade racial e de Educação Indígena, do Campo e Quilombola são fundamentais para a preservação, valorização e reconhecimento dos saberes originários, dos conhecimentos que permanecem vivos mesmo diante da tentativa de invisibilização das tradições, religiões, produções artísticas entre outros elementos culturais dos povos tradicionais. Dito de outro modo, essas políticas são essenciais para a realização de uma prática social transgressora de discursos e práticas padronizadoras, hierarquizadoras, monotemáticas e homogeneizadoras.

Uma política que tem convergência e estabelece interfaces positivas com as políticas de igualdade racial, tendo em vista a presença marcante das populações negras no campo e nos assentamentos de reforma agrária, é o Programa Nacional de Educação na Reforma Agrária (PRONERA), uma das mais importantes conquistas dos movimentos sociais do campo, em que se destaca a participação do Movimento dos Trabalhadores Rurais Sem Terra 
(MST). Merece destaque a linha de ação do programa que, por meio do fortalecimento da educação em acampamentos e assentamentos de Reforma Agrária, voltou-se para formas de produção autônomas, renováveis e autossuficientes, integradas ao desenvolvimento local e regional, visando fortalecer o meio rural enquanto território de vida em todas as suas dimensões: econômicas, sociais, políticas, culturais e éticas.

O Programa de Educação na Reforma Agrária (PRONERA), oriundo das discussões desenvolvidas no I Encontro Nacional de Educadores da Reforma Agrária (ENERA) realizado em 1997, tem sido o principal programa destinado às parcerias de educação na reforma agrária. No PRONERA existem projetos de educação de jovens e adultos visando à alfabetização, escolarização e capacitação dos trabalhadores dos assentamentos da reforma agrária, além de projetos de formação inicial como a Pedagogia da Terra e a Licenciatura em Educação do Campo. Existem projetos de formação continuada como a especialização lato sensu em Educação do Campo. Os cursos de Letras, História, Geografia e Agronomia também são desenvolvidos no contexto do PRONERA. (SOUZA, 2008, p. 1091).

A referência feita ao PRONERA evidencia os resultados das mobilizações dos movimentos sociais do campo na luta pela reforma agrária e pela educação dos povos camponeses. Embora não seja uma política pública declaradamente voltada às ações étnicoraciais, esta possibilitou o acesso à educação nos diferentes níveis e modalidades à população negra camponesa, em que se incluem as comunidades quilombolas e muitas outras comunidades do campo, que não se reconhecem como quilombolas - constituídas em sua grande maioria por populações negras e que nem sempre visibilizam a educação para a igualdade racial como elemento central em suas reivindicações.

Conforme dito, o programa não se restringe à oferta de escolarização às populações assentadas da reforma agrária, assegurando as condições de acesso à educação pública para essas populações, mas sobretudo volta-se ao fortalecimento do protagonismo social, contribuindo com o empoderamento dos coletivos e movimentos sociais das populações assentadas em suas lutas pela efetivação de políticas públicas que propiciem melhorias no desenvolvimento dos assentamentos rurais e nas condições de vida no campo, por meio da formação educacional e qualificação dos profissionais que desenvolvem atividades educacionais e técnicas nos assentamentos.

Do ponto de vista legal, o Decreto $\mathrm{n}^{0}$ 7.352, de 4 de novembro de 2010 dispõe sobre a Política de Educação do Campo e o PRONERA, atribuindo à Educação do Campo a condição potencial de política de Estado, tendo em vista o estabelecimento de que a Política de Educação do Campo destina-se à ampliação e qualificação da oferta de educação básica e superior aos povos tradicionais e camponeses. De acordo com o decreto, a responsabilidade 
deve ser compartilhada entre todos os entes federados para fortalecer a materialização da educação como direito no campo. No que diz respeito ao governo federal, este é responsável pela criação e implementação de mecanismos que assegurem a manutenção e o desenvolvimento da educação nos territórios do campo com vista a superar a defasagem histórica de acesso dos povos tradicionais e camponeses à escolarização, especialmente nos níveis mais elevados de ensino.

O referido decreto regulamentou o PRONERA, já autorizado pela Lei 11.947 , de 16 de junho de 2009, reconhecendo-o como uma política pública construída em torno do princípio da universalização da educação pública com a gestão compartilhada no tripé Estado-Universidades-Movimentos Sociais e Sindicais Populares do Campo, que afirma o princípio da participação ativa dos sujeitos na elaboração de políticas públicas com fundamentos democráticos. (FONEC, 2020).

$\mathrm{O}$ esforço coletivo empreendido pelo protagonismo dos movimentos sociais e fortalecido com a definição dos marcos regulatórios explicitados impacta no reconhecimento da educação dos povos do campo como direito ainda por ser efetivado plenamente e proporciona a criação e o desenvolvimento de outros projetos e programas que afirmam a diversidade socioterritorial da Educação do Campo: PROJOVEM Campo Saberes da Terra, Programa de Apoio à Formação Superior em Licenciatura em Educação do Campo - PROCAMPO, Programa Escola da Terra, Programa Institucional de Bolsas de Iniciação à Docência- PIBID Diversidade, Residência Agrária, o Programa Nacional do Livro Didático Campo - PNLDC, Observatório da Educação do Campo, as bolsas específicas para estudantes indígenas e quilombolas, Programa Nacional de Educação do Campo - PRONACAMPO, entre outras. Ainda que com imensas limitações, esses projetos e programas significam a conquista de fundos públicos para a garantia do direito à educação dos povos tradicionais e camponeses.

Tais políticas públicas refletem os espaços de resistência construídos pelo protagonismo dos movimentos sociais dos povos tradicionais e dos camponeses na luta pela superação do modo de produção capitalista (assentado na exploração do ser humano sob todas as formas, na geração incessante de lucro e na extração permanente de mais-valia) e pela afirmação da associação livre dos trabalhadores, da solidariedade e da justa distribuição social da riqueza construída coletivamente pelos seres humanos. (FONEC, 2018).

A trajetória de implantação dessas políticas públicas revela-se como espaço de ampliação do acesso da população camponesa, afro-brasileira e dos povos indígenas à educação básica e ao ensino superior em nosso país. Para fins da presente discussão, ressaltamos a interlocução das políticas de igualdade racial e da Educação Indígena, do 
Campo e Quilombola com as políticas públicas direcionadas aos povos do campo, tendo em vista que uma das características marcantes em todas elas é a relação com o território, as raízes que remetem à ancestralidade, a terra não vista como mercadoria, mas elemento primordial para produção da existência e sustentabilidade da vida.

Nesse sentido, salientamos que a dimensão dos saberes tradicionais e os aspectos culturais da identidade africana, afro-brasileira, indígena e camponesa precisam se fortalecer no cenário educacional brasileiro. É preciso garantir que os elementos constitutivos da cosmovisão africana, indígena e camponesa, que ainda não ocupam o devido lugar no campo educacional brasileiro, estejam presentes não somente nos currículos, mas no cotidiano escolar e social brasileiro.

Abordar as manifestações culturais tradicionais presentes na comunidade e
dialogar com a memória desses sujeitos enquanto trabalhadores rurais,
filhos e/ou netos de festeiros. Isso abrange a organização política desses
grupos, a herança musical das famílias dos(as) jovens; as visões de mundo
que os fortalecem para o enfrentamento diário contra o racismo existente na
sociedade em que se inserem; a posição que os(as) jovens ocupam na
manutenção dessa herança ancestral e os conflitos que isso gera em
confronto com a modernidade [...]. (BRASIL, 2006, p. 112).

A partir desses pressupostos, o racismo deve ser combatido permanentemente. Este deve ser tema de discussão nas escolas, universidades e/ou outros espaços sociais de formação dos sujeitos. A mudança do paradigma eurocêntrico deve ocorrer no diálogo aberto tanto nas instituições de ensino, assim como fora delas. Para além das questões econômicosociais que assolam a grande maioria da população negra e indígena, é preciso promover uma mudança no imaginário coletivo. Em outras palavras, é preciso garantir a presença e a permanência de negros, indígenas e camponeses nos espaços políticos e sociais ocupados majoritariamente pelos brancos (principalmente da elite econômica): no parlamento, nas universidades, nos órgãos e cargos públicos etc.

Como nos diz Freire (1999, p. 67), "qualquer discriminação é imoral e lutar contra ela é dever por mais que reconheça a força dos condicionamentos a enfrentar". Assim, é preciso superar a visão de que a história dos africanos, afro-brasileiros, indígenas e camponeses deve ser reportada à escravidão, à exploração e à subalternização. Esses povos possuem um legado de saberes, conhecimentos, tradições, religiosidade que foram (e são) essenciais para nossa constituição enquanto nação. Isso quer dizer que a reflexão e a crítica necessárias ao enfrentamento ao racismo e à discriminação devem passar pelo rompimento com as imagens negativas atribuídas aos negros, indígenas e camponeses. 


\section{Ameaças às políticas públicas de igualdade racial, de Educação Indígena, do Campo e Quilombola: o atual contexto brasileiro}

O atual cenário político brasileiro evidencia retrocessos políticos, econômicos, sociais educacionais e culturais, criando um clima permanente de tensionamento entre as classes, grupos, segmentos, etnias, raças, com a ofensiva dos diversos setores do capital sobre o governo e o Congresso Nacional na perspectiva de redução de direitos humanos e sociais e plena liberdade para que os donos dos negócios possam precarizar ainda mais o trabalho, os empregos e os salários. Em relação às políticas públicas educacionais, especialmente aquelas direcionadas aos povos indígenas, quilombolas e camponeses, é possível afirmar que a perspectiva é de desmonte, impactando duramente as conquistas dos movimentos sociais expressas nas ações afirmativas e de igualdade racial.

Dois documentos produzidos pelos coletivos que integram o Movimento da Educação do Campo no Brasil, no período mais recente, denunciam essa situação: a Carta-Manifesto do Fórum Nacional de Educação do Campo (FONEC) resultante do Encontro Nacional 20 anos da Educação do Campo e do PRONERA (2018) e a Nota em defesa do PRONERA (2020). O primeiro foi aprovado na plenária final do Encontro Nacional 20 anos da Educação do Campo e PRONERA, que ocorreu de 12 a 15 de junho de 2018 na Universidade de Brasília e contou com a participação de mais de mil camponeses e educadores das escolas de educação básica e superior, dos Centros Familiares de Formação por Alternância, estudantes da Educação do Campo, entre outros atores sociais.

O segundo, lançado em Brasília no dia 25 de fevereiro de 2020 pelo FONEC, constituído por representantes dos Fóruns e Comitês Estaduais de Educação do Campo e dos movimentos sociais camponeses, reporta-se a uma das medidas tomadas pelo presidente Jair Bolsonaro, que tem gerado consequências na vida dos povos tradicionais e camponeses e em diferentes setores da sociedade: é o caso do Decreto $\mathrm{N}^{\circ} 10.252$ de 20 de fevereiro de 2020.

Mais do que alterar a estrutura regimental e de cargos, o Decreto altera
profundamente as competências do órgão. A autarquia deixa de ter
competências de formulação. Toda a política agrária fica subordinada à
formulação do Ministério da Agricultura, Pecuária e Abastecimento -
MAPA, em especial a destinação das terras públicas, a seleção de famílias
para assentamentos de Reforma Agrária e a normatização e formação de
grupos para elaboração de estudos de identificação e demarcação de terras
remanescentes de quilombos. (FONEC, 2020, p. O1).

Infelizmente, as manifestações do atual presidente do Brasil veiculadas nos órgãos de imprensa e por meio das redes sociais - muitas vezes eivadas de informações não verídicas, mas 
que encontram ressonância entre seus apoiadores - têm sido nefastas à garantia dos direitos dos povos tradicionais, indígenas e camponeses, assim com à educação, à demarcação dos territórios tradicionais, às políticas de ação afirmativa, à reforma agrária e a outras conquistas resultantes dos esforços por parte dos movimentos sociais representativos desses povos.

Especificamente, em relação ao território destinado aos povos tradicionais, indígenas e camponeses, é possível constatar o avanço dos interesses do agro e hidronegócio e das grandes empresas mineradoras representados na Câmara Federal e no Senado por parlamentares que atuam, estritamente, em defesa dos interesses das grandes corporações vinculadas ao capital nacional e internacional.

\begin{abstract}
Acerca de questões diretamente ligadas ao campo, vale destacar que a suspensão da política de Reforma Agrária, a prioridade da política de titulação e consolidação de assentamentos, o desmonte da política de assistência técnica, as medidas que sinalizam a redução das áreas quilombolas e indígenas demarcadas, a permissão para aquisição de terras por estrangeiros revelam-se em favor da expansão do agronegócio. Tais pontos impedem um projeto de desenvolvimento comprometido com a soberania alimentar da população brasileira e impõem o acirramento das já históricas estatísticas de violência, em todas as suas formas. (FONEC, 2018, p. 01).
\end{abstract}

Todas essas questões ganham força diante do discurso da bancada ruralista no Congresso Nacional e seus apoiadores, que recorrentemente se manifestam caracterizando os territórios camponeses como atrasados, subdesenvolvidos e, nessa perspectiva, apresentam para a solução de seus problemas a superexploração dos territórios (a exemplo da Amazônia) sob o protagonismo do agronegócio com a legitimação do Estado e com a justificativa do "desenvolvimento econômico".

Desta forma, a participação da sociedade civil nos espaços de deliberação definidos pelo Estado, tem sido direcionada para o âmbito da legitimação e continuidade da implementação de projetos de interesse do capital. Estas instâncias "legais" de participação convertem-se em mecanismos que disciplinam as relações de forças e forjam consensos, controlando a circulação e a produção dos discursos. Como ocorre, por exemplo, nas "consultas públicas", junto à população, sobre a construção de grandes projetos de "Desenvolvimento", que, em última análise têm por finalidade maximizar a eliminação de prioridades e reivindicações oriundas da população (IBERÊ, 2015, p. 115).

Diante dessa lógica, não há limites para se garantir a acumulação e os imperativos do lucro dessas grandes corporações nacionais e internacionais de tal maneira que os territórios dos povos indígenas, quilombolas e camponeses continuam a ser invadidos/tomados, em grande medida de forma ilegal e com ações de violência e extermínio contra lideranças de movimentos sociais desses povos, devido à expansão da monocultura agrícola, a pecuária 
extensiva, o garimpo ilegal, a construção de barragens, a exploração de madeira ilegal entre outras formas de espoliação praticadas por essas corporações.

Cumpre salientar que esse paradigma político-econômico ultrapassa as fronteiras brasileiras, isto é, a lógica globalizada do capital, por meio dos acordos regionais e internacionais, sustenta os lucros das grandes corporações e mantém o subdesenvolvimento das nações latino-americanas que permanecem sob a condição de subalternizadas. Dito de outro modo, os processos neocoloniais estão se tornando cada vez mais explícitos e podem ser claramente evidenciados através do racismo, dos preconceitos contra povos imigrantes e por meio dos discursos de ódio on-line, que têm sempre a intenção de desqualificar o diferente e inferiorizar os povos tradicionais, indígenas, quilombolas e camponeses.

Diante disso, o país segue cegamente a política imposta pelos organismos internacionais e para piorar ainda mais a situação, o presidente Jair Bolsonaro busca imitar o que Donald Trump vem fazendo nos Estados Unidos. A soberania do país está sendo subsumida aos interesses do grande capital e, infelizmente, voltamos a ser vistos apenas como um território de exploração em uma nova lógica, mais sutil, entretanto mais perversa, racista e exterminadora.

Esses elementos evidenciam a relevância de se pensar no antirracismo sem desconsiderar a luta das classes trabalhadoras nem reduzir a temática das políticas de igualdade racial à questão da luta de classes,

[...] mas, é também à partir de uma concepção marxista, que podemos compreender a centralidade do racismo, sobretudo científico, no processo de desenvolvimento e expansão do capitalismo, como também da própria manutenção de uma relação centrada na desigualdade racial, ainda nos dias de hoje. Portanto, quando pensamos na exploração da classe trabalhadora, essa deve estar articulada às relações de opressões implícitas. É importante questionarmos que classe é essa e é constituída por estratos oprimidos, que ocupam uma escala ainda mais degradante no que se refere ao trabalho, às condições de vida e relações sociais. (SILVA, 2019, p. 3).

Vale ressaltar que o racismo se manifesta, também, por meio da desigualdade social, uma vez que a grande maioria da população negra, quilombola, indígena e camponesa vive em condições precárias, seja nas favelas dos grandes centros urbanos, seja nos diferentes territórios rurais do Brasil. A inferiorização dessa parcela da sociedade é refletida na ocupação de postos de trabalho em condições degradantes, no baixo nível de escolaridade que possuem, no seu difícil acesso aos serviços essenciais como: moradia, saneamento básico, saúde etc. Para além disso, temos a desvalorização e/ou a negação de sua história, saberes, religiões, tradições e cultura. 
Portanto, faz sentido apreendermos que a luta contra o racismo deve estar articulada à luta de classes e ter caráter internacionalista, pois, se o racismo é intrínseco ao viés econômico, político e ideológico da sociedade burguesa, somente a supressão dessa sociedade pode eliminar a base de exploração e opressão racial. Mas, se o racismo está emaranhado na cultura burguesa, no pensamento e nas ações dos sujeitos e instituições, romper com ele exige explicitá-lo e combatê-lo também na sociedade burguesa, pois, sabemos que as suas consequências são agravadas ainda mais em contexto de crises do capital, além de perpetuadas constantemente (SILVA, 2019, p. 6).

Essas reflexões são pertinentes quando vivemos num cenário de aprofundamento da crise política no país com o recrudescimento do conservadorismo, que invade o âmbito da política econômica e social no Brasil, e a implementação de contrarreformas antidemocráticas capitaneadas por forças políticas de orientação mercantil, ruralista, religiosa e paramilitar, que se fortaleceram no governo do presidente Bolsonaro após o resultado das eleições de 2018.

A situação se tornou ainda mais grave, tendo em vista o enfrentamento da pandemia do Covid 19, que provocou alterações profundas na rotina mundial com a utilização do distanciamento social como medida mais eficaz para o combate à disseminação do vírus, recomendada pela Organização Mundial da Saúde.

A paralisação das atividades comerciais de muitos setores produtivos, a necessidade de evitar a existência de aglomeração como estratégia de prevenir a contaminação em massa das pessoas, a importância de fortalecer o setor da saúde pública e o financiamento do Estado para as políticas de assistência aos mais vulneráveis provocaram reações nas elites e grupos empresariais do país que, sob a liderança do presidente da República, têm fortalecido uma visão negacionista da pandemia, estimulando a população a descumprir o distanciamento social e aproveitando a crise para avançar com o projeto autoritário, rentista e de desmantelamento das instituições que integram a sociedade de direitos, como o Supremo Tribunal Federal e o Congresso Nacional.

Nesse cenário sombrio em que a democracia está sendo amputada, os direitos sociais historicamente conquistados estão sendo extintos e as consequências recaem sobre os segmentos mais vulneráveis da população brasileira - em que se incluem as classes trabalhadoras, as mulheres, idosos, jovens, crianças, povos indígenas, tradicionais e camponeses.

As classes trabalhadoras e os movimentos sociais representativos desses segmentos de agentes propositores de mudanças passam a ser vistos como agrupamentos interessados na desordem social e sofrem um processo intenso de criminalização com o extermínio de suas principais lideranças, especialmente, aquelas que estão vinculadas à defesa de seus territórios: indígenas, quilombolas, extrativistas e camponeses. 
As políticas públicas de igualdade racial, de Educação do Campo, Indígena e Quilombola e todas aquelas destinadas a universalizar direitos às classes trabalhadoras estão continuamente sendo ameaçadas, não chegando a serem extintas propriamente, mas sendo esvaziadas com a retirada de seus princípios basilares e dos recursos do fundo público que as viabilizam.

Essa situação, que envolve toda uma arquitetura da destruição de políticas e direitos em curso no Brasil, tem exigido a unidade das classes trabalhadoras e dos movimentos sociais representativos dos povos tradicionais, indígenas, camponeses e dos demais segmentos subalternizados para a defesa intransigente de suas demandas e de políticas que assegurem a dignidade humana, a preservação da vida e da natureza, a reforma agrária, a demarcação territorial, a afirmação de suas culturas e saberes e a soberania nacional.

\section{Considerações finais}

A luta dos movimentos sociais representativos dos povos tradicionais, indígenas, negros, quilombolas e camponeses para garantir os direitos sociais expressos na Constituição Federal não é uma luta apenas deles, mas de todas as classes trabalhadoras e demais grupos subalternizados que vivem um processo dramático de retrocesso de garantia de direitos jamais visto na história brasileira e mundial.

As políticas de igualdade racial, mais especificamente em suas interfaces com as políticas de Educação Indígena, Quilombola e do Campo, sofrem ingerência governamental, uma vez que a lógica imperialista a que o país se submete é contrária aos princípios que regem tais políticas. Existe neste cenário uma disputa acirrada entre dois projetos que se estabelecem: de um lado, pelos apoiadores de um projeto que visa à exploração e subalternização dos seres humanos; e de outro, pelos defensores de um projeto que visa à preservação dos nossos ecossistemas, das culturas e dos conhecimentos científicos e tradicionais e à valorização dos seres humanos enquanto sujeitos históricos e diversos.

Reunir esforços para garantir a continuação e a afirmação das políticas de igualdade racial em suas interfaces com as políticas de Educação Indígena, Quilombola e do Campo não pode ser encarado apenas como interesse dos povos tradicionais, indígenas e camponeses, mas de todo o povo brasileiro. Ficar parado "dando milho aos pombos" pode nos tornar cúmplices das atrocidades que estão sendo efetivadas pelo atual governo brasileiro em articulação com o imperialismo norte americano. 


\section{Referências}

BARBOSA, W. N. Neocolonialismo: um conceito atual? In: SANKOFA - Revista de História da África e de Estudos da Diáspora Africana Ano IV, No 8, Dezembro/2011. Disponível em: $<$ http://www.revistas.usp.br/sankofa/article/download/88803/91686/ >. Acesso em: 02/04/2020. DOI: https://doi.org/10.11606/issn.1983-6023.sank.2011.88803.

BRASIL. Constituição da República Federativa do Brasil [recurso eletrônico]. — Brasília: Supremo Tribunal Federal, Secretaria de Documentação, 2019. Disponível em: $<$ https://www.stf.jus.br/arquivo/cms/legislacaoConstituicao/anexo/CF.pdf > . Acesso em: 09/04/2020.

BRASIL. Lei no 10.639/2003. Altera a Lei no 9.394, de 20 de dezembro de 1996, que estabelece as diretrizes e bases da educação nacional, para incluir no currículo oficial da Rede de Ensino a obrigatoriedade da temática "História e Cultura Afro-Brasileira", e dá outras providências. Disponível em: <http://www.planalto.gov.br/ccivil 03/leis/2003/110.639.htm>. Acesso em 09/04/2020.

BRASIL. Lei $n^{\circ}$ 11.645/2008. Altera a Lei no 9.394, de 20 de dezembro de 1996, modificada pela Lei $n^{\circ}$ 10.639, de 9 de janeiro de 2003, que estabelece as diretrizes e bases da educação nacional, para incluir no currículo oficial da rede de ensino a obrigatoriedade da temática "História e Cultura AfroBrasileira e Indígena” Disponível em: <http://www.planalto.gov.br/ccivil 03/ Ato20072010/2008/Lei/L1 1645.htm>. Acesso em 09/04/2020.

BRASIL. Ministério da Educação. Secretaria de Educação Continuada, Alfabetização e Diversidade. Orientações e Ações para a Educação das Relações Étnico-Raciais. Brasília: SECAD, 2006. Disponível em: <http://portal.mec.gov.br/dmdocuments/orientacoes_etnicoraciais.pdf>. Acesso em: 11/04/2020.

BRASIL. Ministério da Educação. Conselho Nacional de Educação/Conselho Pleno/DF. Resolução $n^{\circ}$ 01, de 17 de junho de 2004. Institui Diretrizes Curriculares Nacionais para a Educação das Relações ÉtnicoRaciais e para o Ensino de História e Cultura Afro-Brasileira e Africana. Disponível em: <http://portal.mec.gov.br/cne/arquivos/pdf/res012004.pdf $>$. Acesso em: 11/04/2020.

BRASIL. Ministério da Educação. Conselho Nacional de Educação/ Câmara de Educação Básica. Resolução no 8, de 20 de novembro de 2012. Define Diretrizes Curriculares Nacionais para a Educação Escolar Quilombola na Educação Básica. Disponível em:

$<$ http:/ portal.mec.gov.br/index.php?option=com_docman\&view=download\&alias $=11963$ rceb008-12-pdf\&category_slug=novembro-2012-pdf\&Itemid=30192>. Acesso em: 11/04/2020.

BRASIL. Decreto $\mathrm{n}^{\circ}$ 7.352, de 4 de novembro de 2010. Dispõe sobre a política de educação do campo e o Programa Nacional de Educação na Reforma Agrária - PRONERA. Disponível em: <http://www.planalto.gov.br/CCIVIL_03/_Ato2007-2010/2010/Decreto/D7352.htm>. Acesso em 12/04/2020.

FÓRUM NACIONAL DE EDUCAÇÃO DO CAMPO (FONEC). Nota em defesa do PRONERA e do direito à Educação do Campo. 25 de fevereiro de 2020. Disponível em: $<$ https://mst.org.br/2020/02/28/forum-nacional-de-educacao-do-campo-denunciaextincao-do-pronera/>. Acesso em 30/04/2020. 
FÓRUM NACIONAL DE EDUCAÇÃO DO CAMPO (FONEC). Carta-Manifesto 20 anos da Educação do Campo e PRONERA. Disponível em:

$<$ http://www.enfoc.org.br/noticias/detail/586>. Acesso em: 30/04/2020.

FREIRE, Paulo. Pedagogia da esperança: um reencontro com a pedagogia do oprimido. $6^{\mathrm{a}}$ ed. São Paulo: Paz e Terra, 1999.

IBERÊ, Daniel. IIRSA: A Serpente do Capital: pilhagem, exploração e destruição cultural na América Latina (Santo Antônio e Jirau). Rio Branco: Edufac, 2015.

SANTOS, B. S. O colonialismo insidioso. 2018. Disponível em:

$<$ https://www.publico.pt/2018/03/30/sociedade/opiniao/o-colonialismo-insidioso$1808254>$. Acesso em 02/02/2020.

SILVA, Sandra Regina Vaz da. Diálogos e Tensionamentos na Luta Antirracista e Luta de Classes. Núcleo Interdisciplinar de Estudos e Pesquisas sobre Marx e o Marxismo da Universidade Federal Fluminense (NIEP-Marx/UFF). 2019. Disponível em:

<http://www.niepmarx.blog.br/MM2019/Trabalhos\%20aprovados/MC51/MC513.pdf>.

SOUZA, Maria Antônia de. Educação do campo: políticas, práticas pedagógicas e produção científica. Educação e Sociedade. Campinas, vol. 29, n. 105, p. 1089-1111, set./dez. 2008. DOI: https://doi.org/10.11606/issn.1983-6023.sank.2011.88803. 